\author{
Marquette University \\ e-Publications@Marquette
}

Electrical and Computer Engineering Faculty Research and Publications

$11-2012$

\title{
Stress Monitoring of Post-processed MEMS Silicon Microbridge Structures Using Raman Spectroscopy
}

Lavern A. Starman

Air Force Institute of Technology

Ronald A. Coutu Jr.

Marquette University, ronald.coutu@marquette.edu

Follow this and additional works at: https://epublications.marquette.edu/electric_fac

Part of the Computer Engineering Commons, and the Electrical and Computer Engineering Commons

\section{Recommended Citation}

Starman, Lavern A. and Coutu, Ronald A. Jr., "Stress Monitoring of Post-processed MEMS Silicon Microbridge Structures Using Raman Spectroscopy" (2012). Electrical and Computer Engineering Faculty Research and Publications. 361.

https://epublications.marquette.edu/electric_fac/361 
Marquette University

\section{e-Publications@Marquette}

\section{Electrical and Computer Engineering Faculty Research and Publications/College of Engineering}

This paper is NOT THE PUBLISHED VERSION; but the author's final, peer-reviewed manuscript. The published version may be accessed by following the link in the citation below.

Experimental Mechanics, Vol. 52, No. 9, (November, 2012): 1341-1353. DOI. This article is (C) Springer and permission has been granted for this version to appear in $\underline{\mathrm{e}-}$ Publications@Marquette. Springer does not grant permission for this article to be further copied/distributed or hosted elsewhere without the express permission from Springer.

\section{Contents}

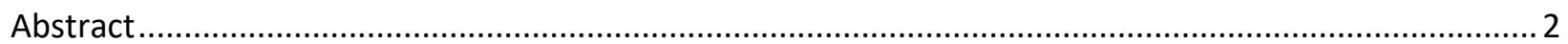

Keywords.......................................................................................................................... 2

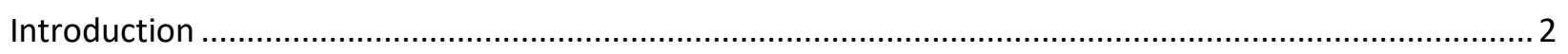

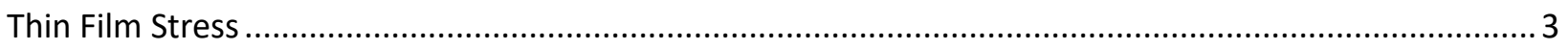

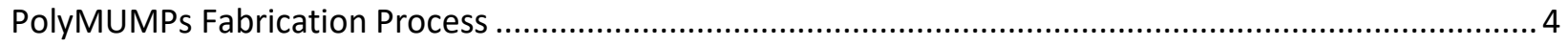

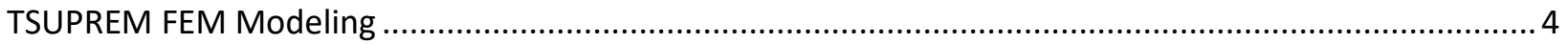

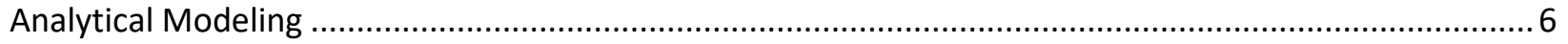

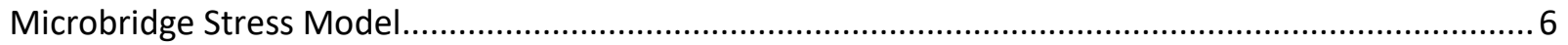

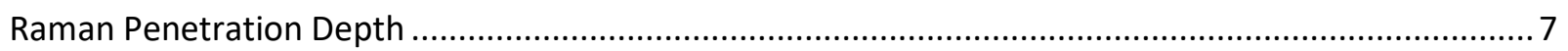

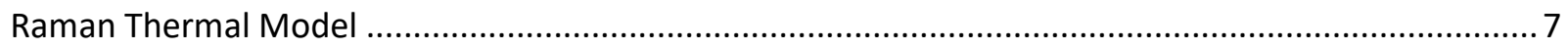

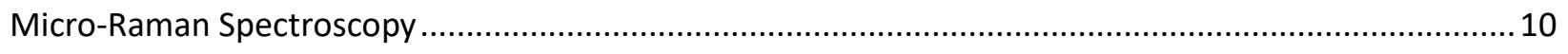

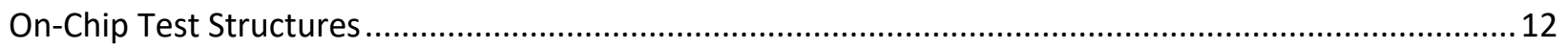

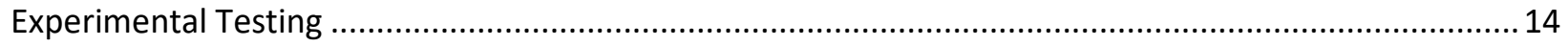

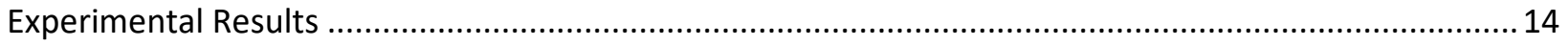

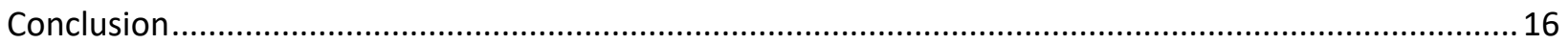

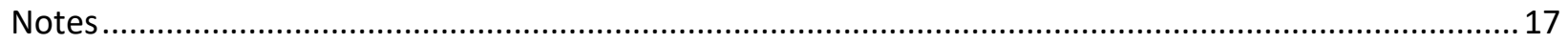

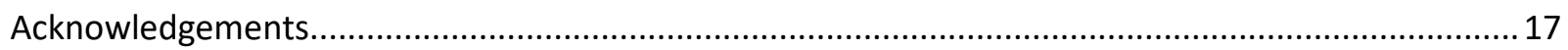




\title{
Stress Monitoring of Post-processed MEMS Silicon Microbridge Structures Using Raman Spectroscopy
}

\section{Starman}

Air Force Institute of Technology, Wright-Patterson Air Force Base, $\mathrm{OH}$

R. Coutu Jr.

Air Force Institute of Technology, Wright-Patterson Air Force Base, OH

\begin{abstract}
Inherent residual stresses during material deposition can have profound effects on the functionality and reliability of fabricated Micro-Electro-Mechanical Systems (MEMS) devices. Residual stress often causes device failure due to curling, buckling, or fracture. Typically, the material properties of thin films used in surface micromachining are not well controlled during deposition. The residual stress; for example, tends to vary significantly for different deposition methods. Currently, few nondestructive techniques are available to measure residual stress in MEMS devices prior to the final release etch. In this research, micro-Raman spectroscopy is used to measure the residual stresses in polysilicon MEMS microbridge devices. This measurement technique was selected since it is nondestructive, fast, and provides the potential for in-situ stress monitoring. Raman spectroscopy residual stress profiles on unreleased and released MEMS microbridge beams are compared to analytical and FEM models to assess the viability of micro-Raman spectroscopy as an in-situ stress measurement technique. Raman spectroscopy was used during post-processing phosphorus ion implants on unreleased MEMS devices to investigate and monitor residual stress levels at key points during the post-processing sequences. As observed through Raman stress profiles and verified using on-chip test structures, the post-processing implants and accompanying anneals resulted in residual stress relaxation of over $90 \%$.
\end{abstract}

Keywords

Raman spectroscopy; Stress; MEMS; Polysilicon; Implants

\section{Introduction}

Due to the small size of MEMS devices, residual stress in the material layers after growth and fabrication play a major role in the successful functionality and reliability of the device. To obtain robust and reliable micromechanical devices, it is essential to understand how processing parameters affect the mechanical properties of individual thin-film layers. The material properties of the structural layers, in particular the stress and stress gradients which depend on the mechanical properties are very important for device performance. Residual stress often causes device failure due to curling, buckling, or fracture. 
However, if the residual stresses can be mapped, and eventually controlled during the manufacturing processes, the MEMS designer will no longer be forced to limit his/her design to account for the intrinsic manufacturing stresses. This research effort builds on the understanding and behavior of thin film silicon as it's scaled down in size. In addition, the characterization and testing of silicon based MEMS to address fundamental mechanical properties (i.e. Young's modulus, residual stress) are presented which can change as a result of fabrication processes and post processing methods. Thus, to exploit the full advantage of conventional MEMS, it is essential to develop fabrication processes which result in lowstress polysilicon films.

Several techniques have been used to characterize the strain in thin films of silicon to include wafer curvature, $\underline{\underline{1}}$ membrane load deflection,,$\underline{2}$ interferometric measurements (IFM) of deflection and curvature and X-ray diffraction. - Previously, micro-Raman spectroscopy was used to measure residual and induced stresses in MEMS structures. ${ }^{4}$ Micro-Raman spectroscopy was selected since it has the advantage of being fast, nondestructive with micrometer spacial resolution, and since it is an optical technique, shows promise as a minimally invasive in situ measurement technique in the manufacture of MEMS devices. In this paper, micro-Raman spectroscopy is used to measure and monitor local and residual stress levels in polysilicon MEMS devices during the post-fabrication phosphorous implants and accompanying $1,100^{\circ} \mathrm{C}$ anneals prior to release. Several groups have shown micro-Raman spectroscopy is an effective technique for the measurement of mechanical stress in silicon $4,5,6,7,8,9,10,11,12,13$ and silicon MEMS devices. $\underline{14}, 15,16,17, \underline{18}, \underline{19}, \underline{20}, \underline{21}$ Raman stress profiles obtained during post-fabrication processes indicate significant stress reduction is possible in the polysilicon layers of the Multi-User MEMS Processes

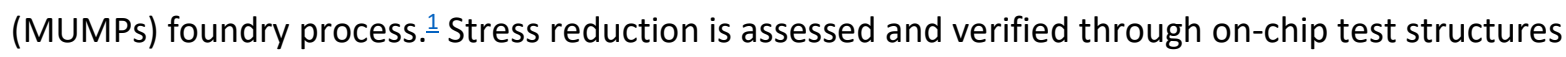
(cantilevers, comb resonators, and buckling beam arrays).

To assess doping and peak concentration depth for maximum residual stress relaxation, a series of phosphorous ion implants was performed. Implant parameters were varied to include implant energy and dopant concentration. The implant energy was set to 100 and $200 \mathrm{keV}$ while the dopant dose varied from $5 \times 10^{15} \mathrm{~cm}^{-2}$ to $1 \times 10^{17} \mathrm{~cm}^{-2}$. This variation provides expected diffused dopant concentration levels ranging from $5 \times 10^{19} \mathrm{~cm}^{-3}$ to $1 \times 10^{21} \mathrm{~cm}^{-2}$. Ion implants were selected to enable precise control of the dopant dose and peak concentration placement within the polysilicon layers. The polysilicon MEMS microbridge structures presented consist of two separate structural layers (Poly1, $2.0 \mu \mathrm{m}$-thick and Poly2, $1.5 \mu \mathrm{m}$-thick) as available from the MUMPs process. ${ }^{1}$

\section{Thin Film Stress}

Stress develops in thin films due to mismatched lattice constants, different thermal expansion coefficients between materials, and as a result of the growth process. $\underline{22}$ Various problems associated with stress include nucleation, propagation of dislocations, and the formation of voids and cracks. $\underline{22}$ The residual stress in thin films may influence dopant diffusion, affect hot carrier degradation, and jeopardize the oxide reliability. Many of these problems become more acute with the increasing complexity and miniaturization of the devices. In the MEMSCAP PolyMUMPs ${ }^{\mathrm{TM}}$ fabrication process, stress gradients exist in the polysilicon layers due to dopant irregularities, dopant uniformity, and the variation in peak dopant concentration levels.

Residual stress and residual stress gradients through the thickness of the polysilicon film are critical constraints on microstructure designs. $\underline{23}, \underline{24}, \underline{25}, \underline{26}, \underline{27}$ If the average stress is compressive for example, micro- 
bridges buckle if longer than a critical length. Stress gradients generate an internal bending moment that causes cantilever beams to warp (up or down) out-of-plane upon release. ${ }^{26}$ As deposited, undoped and non-annealed polysilicon is under compressive stress, for all deposition temperatures using chemical vapor deposition (CVD). ${ }^{-}$The main factor that causes this stress is the grain boundary formation rather than the grain size. ${ }^{-}$Residual stress has a significant dependence on film thickness. The highest compressive stress during deposition is created in the first $200 \mathrm{~nm}$ of film thickness. The stress starts to relax significantly if the film becomes thicker than $350 \mathrm{~nm} . \underline{27}$ Doped polysilicon can have either tensile or compressive residual stress following deposition. Polysilicon that is annealed below the deposition temperature maintains its residual stress. If polysilicon is annealed above its deposition temperature (typically $620^{\circ} \mathrm{C}$ ), the compressive stress starts to decrease with increasing temperature. It is not possible to induce tensile stress by annealing. ${ }^{28}$ A structure with many crystal defects can have the resultant stress lowered through high temperature anneals due to atom rearrangement. Doping and grain structure are important factors which affect the intrinsic stress in polycrystalline silicon. $\underline{29}$

\section{PolyMUMPs Fabrication Process}

The PolyMUMPs fabrication process is outlined in ${ }^{1,4}$ with Fig. 1 (a) illustrating a cross sectional view of all deposition layers and Fig. 1 (b) outlining the thickness of each layer and the layers functionality. Surface material layers are deposited by low pressure chemical vapor deposition (LPCVD). The sacrificial oxide layers, which consist of phosphosilicate glass (PSG) serve two purposes: 1) they define the gaps between structural layers, and 2) they serve as the dopant source for the $1,050^{\circ} \mathrm{C}$ high temperature phosphorus diffusions to reduce the resistivity in the polysilicon structural layers. All surface layers are patterned using standard photolithography techniques and etched using Reactive lon Etching (RIE). The final surface layer, a $0.5 \mu \mathrm{m}$-thick gold metallization layer with a $100 \mathrm{~nm}$ chrome adhesion layer is deposited and patterned using a standard lift-off technique. Lastly, a release etch is performed to remove the sacrificial oxide layers freeing the structural polysilicon layers (Poly1 and Poly2). A typical release etch is performed by immersing the die in room temperature hydrofluoric $(49 \%)$ acid for 2-3 min, methanol rinses to stop the $\mathrm{HF}$ etch, and a supercritical carbon dioxide $\left(\mathrm{CO}_{2}\right)$ rapid dry to minimize stiction.

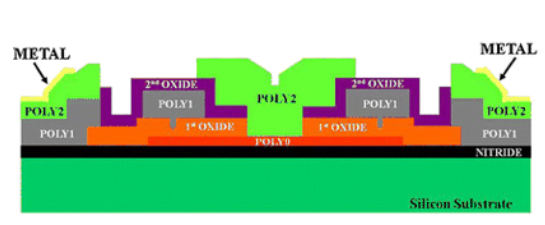

(a)

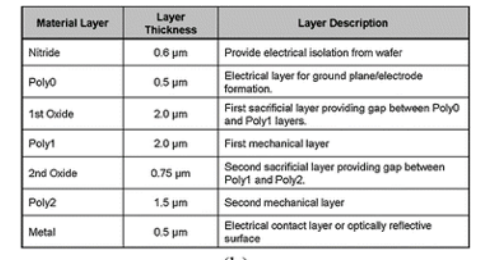

(b)

Fig. 1 MUMPs fabrication layers shown in (a) with layer descriptions and thicknesses given in (b) ${ }^{\underline{1}}$

\section{TSUPREM FEM Modeling}

The PSG diffusion doping method used in the MUMPs process is known to cause stress gradients in the polysilicon structural layers. The polysilicon layers are doped to a concentration level of approximately $1-3 \times 10^{19} \mathrm{~cm}^{-3}$ through the thermal diffusion of phosphorus in the PSG oxide layers which surround the polysilicon layers. ${ }^{1}$ For structures with large width to thickness ratios, $w / t$, the majority of the doping is achieved through diffusion from the oxide layers directly above and below the polysilicon structural layer (vertical diffusion). Sidewall diffusion (lateral diffusion) becomes significant once the structural width is comparable to the layer thickness which can impact the overall doping concentration. To verify 
the lateral diffusion theory and overall doping concentrations, a TSUPREM ${ }^{30}$ model of the PolyMUMPs fabrication process was created based off information provided by the MUMPs foundry and Butler. 1,31 Not all fabrication steps are modeled since the goal is to investigate the phosphorus diffusion profile for the structural layers as a function of the microbridge width $(2-20 \mu \mathrm{m})$. Therefore, only processing steps which affect the phosphorus diffusion profile are included in the model; however, several additional steps are added to the model to provide insight into post-processing implants and anneal studies.

Figure 2 illustrates the phosphorous dopant concentration within the polysilicon structural layers for (from top-to-bottom) 4, 10, and $20 \mu \mathrm{m}$-wide Poly1 and Poly2 beams. The colored-scale legend in Fig. $\underline{2}$ provides the magnitude of the phosphorous concentration for each location in the beams. TSUPREM simulations for Poly1 (Fig. 2(a)) illustrate lateral diffusion is a key contributor in dopant uniformity and increased concentration in narrower Poly1 structures. For the $20 \mu \mathrm{m}$-wide beam shown in Fig. 2(a), the highest dopant concentration is near the edges of the beam indicating lateral diffusion. As beam width increases, the impact of lateral diffusion becomes less significant. Simulation of Poly2 beam structures (Fig. 2(b)) shows no lateral diffusion but still illustrates the nonuniform dopant concentration in the beam structures. In the MUMPs fabrication process, Poly2 structures undergo a single $1,050^{\circ} \mathrm{C}$ anneal which adds to the nonuniformity and reduced dopant concentration as shown by the legend in Fig. 2(b).

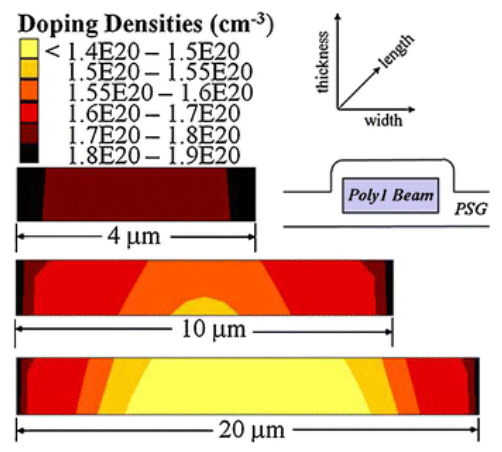

(a)

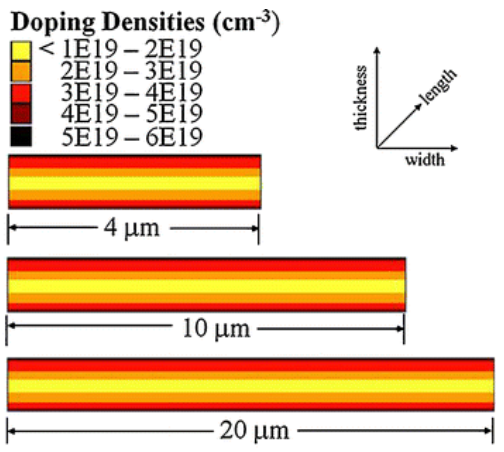

(b)

Fig. 2 (a) TSUPREM diffusion profiles of the MUMPs Poly1 structural layer, and (b) Poly2 structural layer. Beam cross-sections for widths $4 \mu \mathrm{m}, 10 \mu \mathrm{m}$, and $20 \mu \mathrm{m}$

To assess the impacts from ion implantation on the dopant concentration and dopant uniformity which should aid in stress reduction, TSUPREM was used to model the dopant concentration as a function of dopant dose, implant energy, and associated anneal time. Implant Sciences Corporation (ISC) $\frac{32}{2}$ provided a model to assess peak dopant concentration and depth for each implant power level. Since the MUMPs PSG diffusion process provides dopant concentrations of approximately $1-3 \times 10^{19} \mathrm{~cm}^{-3}$, an implant dose of $5 \times 10^{15}$ ions $/ \mathrm{cm}^{2}$ is required to approximately match the background concentration in the structural layers. TSUPREM simulations indicate phosphorous outgassing occurs during post-processing high temperature anneals which inhibit dopant uniformity. Thus, a 50 Á-thick oxide cap was added to the model which covers the polysilicon surfaces to minimize outgassing. Figure $\underline{3}$ is a TSUPREM representation of the $1 \times 10^{16}$ ions $/ \mathrm{cm}^{2}$ phosphorous ion implant for a $10 \mu \mathrm{m}$-wide Poly1 beam (Fig. $\underline{3(a)}$ ) and a $10 \mu \mathrm{m}$-wide Poly2 beam (Fig. $\underline{3(\mathrm{~b})}$ ). As shown, the phosphorous dopant uniformity is significantly improved by the combined phosphorous implant, oxidation, and high temperature anneals. 


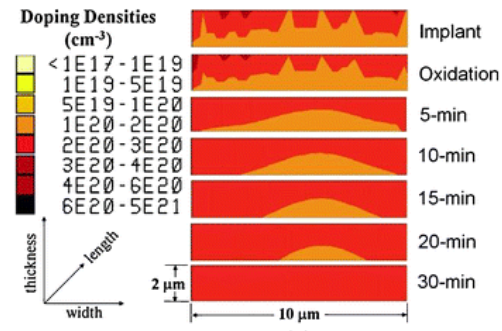

(a)

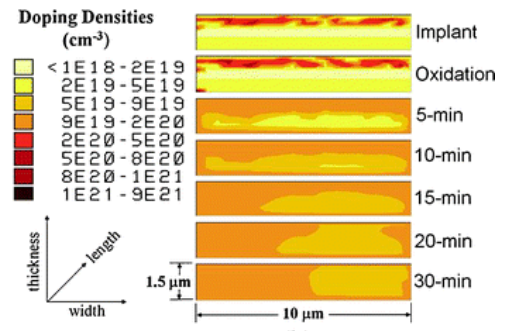

(b)

Fig. 3 TSUPREM doping profiles for the $200 \mathrm{keV}$ phosphorous ion implant $\left(1 \times 10^{16}\right.$ ions $/ \mathrm{cm}^{2}$ dose $)$ with associated post implant anneal times at $1,100^{\circ} \mathrm{C}$ for (a) Poly1 $10 \mu \mathrm{m}$-wide beam, (b) Poly2 $10 \mu \mathrm{m}$-wide beam

From the ISC implantation model, a Gaussian profile for the peak concentration of ions in the material for 100 and $200 \mathrm{keV}$ implant energies were determined to be at depths of 1,353 $\AA$ and 2,852 Á, respectively. Implant doses ranged from $5 \times 10^{15}$ ions $/ \mathrm{cm}^{2}$ to $1 \times 10^{17} \mathrm{ions} / \mathrm{cm}^{2}$ to provide sufficient dopant concentration variations for post stress experimental testing and verification. Peak concentrations for these implant doses ranged from $2.67 \times 10^{20} \mathrm{~cm}^{-3}$ to $9.06 \times 10^{21} \mathrm{~cm}^{-3}$. Integrating these implant doses and $1,100^{\circ} \mathrm{C}$ anneals into our TSUPREM simulations provided implant doping concentration ranges from $5 \times 10^{19}$ to $1 \times 10^{21} \mathrm{~cm}^{-3}$ as shown in Fig. $\underline{3}$.

\section{Analytical Modeling}

\section{Microbridge Stress Model}

Before Raman stress profiles can be verified, an analytical microbridge beam stress profile was generated. The analytical solution provides insight into the characteristic residual stress profiles for a freestanding microbridge beam. The analytical model uses a uniform distributed load $g$ as shown in Fig. $\underline{4(\mathrm{a})} . R_{1}$ and $R_{2}$ are the resultant forces, and $M_{1}$ and $M_{2}$ are the moments about the beam. $\underline{33}$

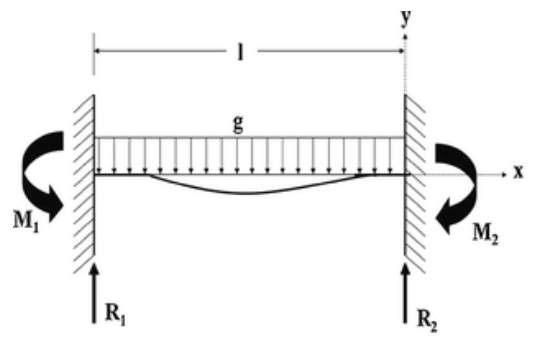

(a)

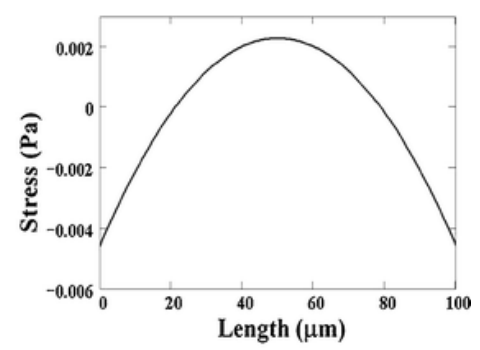

(b)

Fig. 4 (a) Analytical stress model for a MEMS microbridge beam assuming a uniform load and (b) an example stress profile for a uniform load

For a released microbridge beam with a uniform distributed load, the residual stress can be calculated by the following equation $\underline{33}$

$$
\sigma=\frac{M(x) y}{I}[P a](1)
$$

where $M(x)$ is the moment about the beam and is given by 22 


$$
M(x)=\frac{g}{12}\left(6 l x-6 x^{2}-l^{2}\right)[N m](2)
$$

where $g(\mathrm{~N} / \mathrm{m})$ is the distributed load, $l(\mu m)$ is the beam length, and $x(\mu m)$ is a selected position along the length of the beam respectively. For the analytical stress model calculation plotted in Fig. 4(b), the value of $x$ was stepped from $0-100 \mu m$ (model beam length). The compressive residual stress along the length of the beam can be considered a uniform load since this stress will produce a constant uniform applied force within the material layer. Although the simplified stress model magnitudes for this beam are minimal due to the small uniform load, the Raman stress profiles presented later for released microbridge beams clearly resemble the example stress profile shown in Fig. $\underline{4(b)}$.

\section{Raman Penetration Depth}

The Raman signal originates from a volume defined by the wavelength, the diameter of the laser beam, and the properties of the material under stress. A short wavelength laser provides stress information near the surface since the penetration depth is inversely dependent on the absorption coefficient of the material. $-\mathrm{A}$ longer wavelength laser increases the penetration depth which results in a measured stress profile being a weighted average over the penetrated volume. The total scattered light intensity $\left(I_{s}\right)$ integrated from the surface to a depth $d(\mathrm{~nm})$, is given by

$$
I_{s}=I_{o} D \int_{0}^{d} \exp ^{-2 \propto x} d x=\frac{I_{o} D}{2 \propto}\left(1-\exp ^{-2 \propto d}\right)\left[W / \mathrm{cm}^{2}\right]
$$

while that from the depth $d$ to infinity is given by

$$
I_{d}=I_{o} D \int_{d}^{\infty} \exp ^{-2 \alpha x} d x=\frac{I_{o} D}{2 \alpha}\left(\exp ^{-2 \alpha d}\right)\left[W / c m^{2}\right] \text { (4) }
$$

where $I_{0}\left(\mathrm{~W} / \mathrm{cm}^{2}\right), D\left(\mathrm{~cm}^{-1}\right)$, and $\alpha\left(\mathrm{cm}^{-1}\right)$ are the incident light intensity, the Raman scattering cross section, and the photoabsorption coefficient of silicon. $\frac{5}{\text { If }}$ the surface penetration depth, $d_{p}$, is given by the depth that satisfies the relationship $I_{d} /\left(I_{s}+I_{d}\right)=0.1$ (90\% of laser light energy is absorbed within $d$ from the surface), this depth is then given by.

$$
d_{p}=-\frac{\ln 0.1}{2 \propto}=\frac{2.3}{2 \propto}[\mathrm{cm}](5)
$$

Therefore, the penetration depth calculated for the polysilicon material layer is approximately $770 \mathrm{~nm}$ for a $514.5 \mathrm{~nm}$ laser.

\section{Raman Thermal Model}

Since shifts in the Raman spectra (see Fig. $\underline{6(a)}$ ) are sensitive to both temperature and stress, an analytical model is used to estimate the temperature rise in the MEMS microbridge beam due to laser heating. An analytical thermal model based on the various mechanisms of heat loss in the structure was developed and is shown in Fig. $\underline{5(a)}$. Figure $\underline{5(a)}$ identifies four heat loss processes which exist for dissipating heat buildup in a microbridge beam: (1) $H_{\text {bridge }}$-heat conduction through the microbridge; 
(2) $H_{\text {conduction }}$ - heat conduction through the surrounding gas into the substrate; (3) $H_{\text {convection }}$-heat loss through convection into the surrounding gas; and (4) $H_{\text {radiation }}$-heat loss through thermal radiation. $\frac{31,34}{}$ Since all micro Raman spectroscopy tests are accomplished in ambient air with no forced gas flow across the device under test, conduction and convection heat losses

(i.e. $H_{\text {conduction }}$ and $H_{\text {convection }}$ ) into the surrounding gas will be minimal. Figure $5(\mathrm{~b})$ shows an equivalent thermal circuit model derived from the heat loss mechanisms in Fig. $\underline{5(a)}$. Similar thermal circuit models have been used to model the behavior of MEMS lateral thermal actuators and thermal piston micromirrors. $\frac{31,34,35}{}$ The components in the thermal circuit model include: $G_{b}$-thermal conductance for heat flow through the beam, $G_{g}$-thermal conductance for heat flow through the surrounding gas to the substrate, $C_{b}$-thermal capacity of the beam, $I_{b}$-represents the laser power into the system, $T_{b}$-the beam temperature, and $T_{s}$-the substrate temperature. $\underline{31}, \underline{34}$

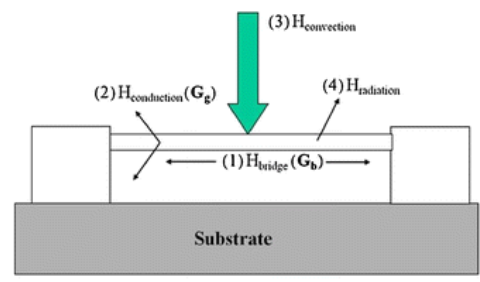

(a)

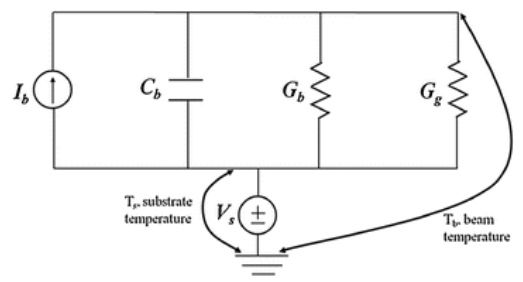

(b)

Fig. 5 (a) Heat loss mechanisms for a polysilicon microbridge ${ }^{20,23}$ and (b) an equivalent thermal circuit model

When using Raman spectroscopy, heat generation due to laser heating must be eliminated or significantly reduced to minimize thermal effects on the Raman stress profiles. Thus, the thermal radiation conductance component is omitted in the thermal circuit model of Fig. $5(b)$ since the device will not operate at a temperature high enough to generate substantial thermal radiation.

The power provided to the system, $I_{b}$, is the optical power $P_{o}$ not reflected by the beam surface which is given by $I_{b}=P_{o}\left(1-R_{\text {beam }}(W) ; \underline{31}\right.$ where $R_{\text {beam }}$ is the reflectance of the beam surface. The measured reflectance for both MUMPs polysilicon structural layers is approximately $31 \%$ for the Raman laser wavelength of $514.5 \mathrm{~nm}$. The laser power was measured to be $2.4 \mathrm{~mW}$ near the surface of the microbridge beam.

Thermal energy deposited on the beam is conducted primarily to the substrate through the polysilicon beam $\left(G_{b}\right)$ and at a far reduced level through the volume of gas directly beneath the beam $\left(G_{g}\right)$. Three thermal model assumptions include: (1) the beam has a high thermal conductivity so its temperature remains approximately uniform; (2) the substrate acts as an infinite heat sink at room temperature $\left(T_{s}=25^{\circ} \mathrm{C}\right)$; and (3) the heat loss or transfer due to radiation is negligible. The numerical values for the equivalent thermal model components in Fig. $5(\mathrm{~b})$ are calculated using the physical dimensions of the microbridge structure and the material properties of polysilicon and the surrounding gas (ambient air). In the thermal model circuit, the equations to determine $C_{b}, G_{b}$, and $G_{g}$ are given as: $\underline{31}, \underline{34}$

$$
\begin{aligned}
C_{b} & =p_{b} C_{p} w t l[J / K] \text { (6) } \\
G_{b} & =\frac{N_{\text {poly }} w t}{l}[W / K](7)
\end{aligned}
$$




$$
G_{g}=\frac{F_{S} N_{a i r} w l}{h}[W / K](8)
$$

where $\rho_{b}$ is the density of the beam $\left(2.33 \times 10^{3} \mathrm{~kg} / \mathrm{m}^{3}\right), C_{p}$ is the thermal capacity of the polysilicon beam $\left(7.54 \times 10^{2} \mathrm{~J} / \mathrm{kg}-\mathrm{K}\right)$, and $N_{\text {poly }}(30 \mathrm{~W} / \mathrm{m}-\mathrm{K})$ and $N_{\text {air }}(0.02 \mathrm{~W} / \mathrm{m}-\mathrm{K})$ are the thermal conductivities of the polysilicon and the surrounding gas. ${ }^{34} F_{S}$ (unitless) is the shape factor which accounts for the impact of the shape of the element on the heat-transfer to the gas, and $h(\mu \mathrm{m})$ is the gap distance between the microbridge beam and the substrate. The length, width, and thickness of the beam are represented by $l, w$, and $t$ respectively.

The shape factor $F_{S}$ accounts for fringing heat flux effects which are a function of the shape of the element and its elevation above the substrate. $\stackrel{34}{-}$ For arbitrary shapes, $F_{S}$ is found by using computationally intense numerical methods or conformal mapping. However, if a Manhattan (rectangular) geometry is assumed, the calculation for the shape factor can be accurately and simply reduced to the empirical equation: $\frac{34,35}{35}$

$$
F_{S} \frac{t}{w}\left(\frac{2 s}{t}+1\right)+1[\text { unitles }](9)
$$

where $s$ is the elevation above the substrate and $t$ and $w$ are the thickness and width of the element. For Manhattan shaped elements, this equation is accurate to within five percent of the numerically derived method used by Mastrangelo. $\stackrel{31,34}{2}$ For a polysilicon beam with dimensions of $10 \mu \mathrm{m}$-wide by $100 \mu \mathrm{m}$-long beam, the shape factor is 1.6 for Poly1 and 1.55 for Poly2 respectively. From Fig. $5(\mathrm{~b})$, the temperature rise of the beam is

$$
T_{b}=P_{o}\left(1-R_{\text {beam })} Z[K](10)\right.
$$

where $Z$ is equal to $1 / Y$ and $Y$ is given by

$$
Y=\sqrt{Z_{1}^{2}+C_{b}^{2}}\left[\mathrm{kgm}^{2} / S^{3} K\right]
$$

where $Z_{1}\left(\mathrm{kgm}^{2} / \mathrm{s}^{3} \mathrm{~K}\right)$ is the parallel combination of the thermal conductance for heat flow through the element $G_{b}$ and the thermal conductance for heat flow through the surrounding gas to the substrate $G_{g}$. Thus, the theoretical calculated temperature rise due to the Raman laser power set to $2.40 \mathrm{~mW}$ is approximately $1.225^{\circ} \mathrm{C}$ for a Poly1 beam and $1.381^{\circ} \mathrm{C}$ for a Poly2 beam. A temperature increase of $4^{\circ} \mathrm{C}$ results in a $-0.01 \mathrm{Rcm}^{-1}$ shift (the unit ' $\mathrm{Rcm}^{-1}$, denotes "relative $\mathrm{cm}^{-1}$ ") in the Raman spectrum which equates to an increase in compressive stress of approximately $-3.757 \mathrm{MPa} \cdot \frac{36}{6}$ Thus, the theoretical temperature rise values will induce compressive stress values of approximately $-1.726 \mathrm{MPa}$ and $-1.531 \mathrm{MPa}$ respectively.

To experimentally test this thermal model, a series of Raman scans were performed on released MEMS buckled microbridge beam arrays. Raman scans on the first unbuckled beam in the array for Poly1 $(490 \mu \mathrm{m})$ and Poly2 $(370 \mu \mathrm{m})$ was performed to assess structural heating. If the temperature of the unbuckled beam rises due to the laser, the beam will buckle since an increase in temperature results in an increase in the compressive stress. By using the temperature/stress correlation presented by De Wolf, $\underline{36}$ the measured stress can be determined in both polysilicon layers through the use of our measured Young's modulus values (131 GPa for Poly1 and $162 \mathrm{GPa}$ for Poly2). The calculated compressive stress difference between Poly1 beams with lengths of $490 \mu \mathrm{m}$ (unbuckled) and $500 \mu \mathrm{m}$ 
(buckled) is $-0.285 \mathrm{MPa}$ (equivalent to a temperature increase of $0.30^{\circ} \mathrm{C}$ ). An identical test on Poly2 beams with lengths of $370 \mu \mathrm{m}$ (unbuckled) and $380 \mu \mathrm{m}$ (buckled) gives a compressive stress difference of $-0.46 \mathrm{MPa}$ (equivalent to a temperature increase of $0.49^{\circ} \mathrm{C}$ ). The Raman stress profiles for the Poly2 beam are shown in Fig. $\underline{6(b)}$. Since the $490 \mu \mathrm{m}$ Poly1 beam remained unbuckled following the Raman scan, one can conclude that only minimal thermal effects will occur for the selected $2.40 \mathrm{~mW}$ laser power level used during the Raman scans.

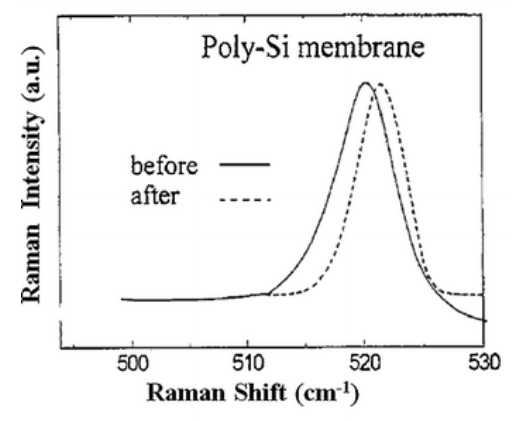

(a)

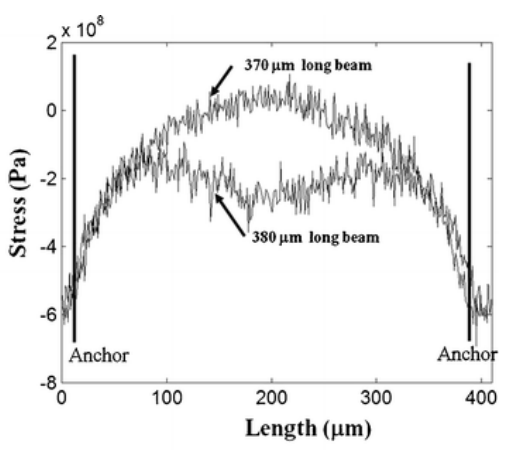

(b)

Fig. 6 (a) An example micro-Raman spectrum illustrating a polysilicon line shift due to temperature or stress, and (b) illustrates micro-Raman stress profiles for Poly2 released beams $370 \mu \mathrm{m}$ (unbuckled) and $380 \mu \mathrm{m}$ (buckled). Following the Raman scan, the $370 \mu \mathrm{m}$ beam remained unbuckled, thus verifying the Raman shift is a result of material stress and not from a significant temperature increase in the microbridge test sample

\section{Micro-Raman Spectroscopy}

In micro-Raman spectroscopy, laser light is focused on the sample through a microscope to a spot size of $\sim 1 \mu \mathrm{m}$ in diameter. A laser beam $(\lambda=514.5 \mathrm{~nm})$ is used to irradiate the sample and the scattered light, which carries the Raman signals, is collected and directed into a spectrometer. The spectrometer measures the intensity of the Raman signal as a function of frequency. For an unstressed sample, the spectrometer measures a reference spectrum. When the sample is placed in a stressed state, the Raman spectrum displays a shift in frequency with respect to the reference spectrum. This frequency shift is a result of residual or induced stress. Figure 7 (a) shows a typical Raman spectra used in this study. The Rayleigh scattering (laser line) is used as a reference to locally and individually calibrate each Raman spectrum. Figure $\underline{7(b)}$ illustrates typical micro-Raman spectroscopy stress profiles for both an unreleased and a released polysilicon beam. As shown in Fig. $\underline{7(b)}$, the released beam stress profile is very similar to the analytical modeled beam stress profile shown in Fig. $\underline{4(b)}$ for a distributed, uniform load.

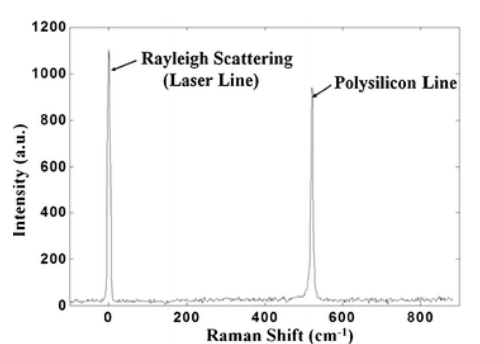

(a)

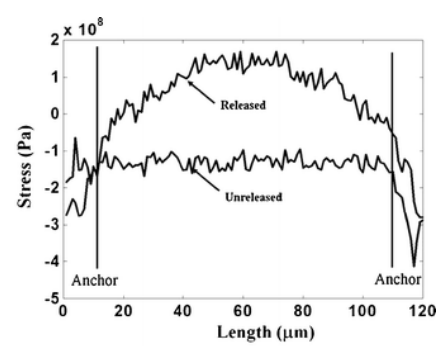

(b)

Fig. 7 (a) Typical spectrum illustrating the source laser line and resultant Raman silicon line, (b) Raman stress profiles for an unreleased and released microbridge beam. Released profile similar to analytical profile shown in Fig. $\underline{4(b)}$ 
Ganesan ${ }^{37}$ was one of the first to show the effects of strain on diamond structured crystals using Raman spectroscopy. The Raman spectra of unstressed silicon has one peak at $520 \mathrm{Rcm}^{-1}$, which is comprised of the frequencies of three $k=0$ optical phonon modes. Using the Raman secular equation (equation $(\underline{12}))$, one can solve for the effect of strain on these optical modes:

$$
\begin{array}{|ccc}
* 20 c p \varepsilon_{11}+q\left(\varepsilon_{22}+\varepsilon_{33}\right)-\lambda_{1} & 2 r \varepsilon_{12} & 2 r \varepsilon_{13} \\
2 r \varepsilon_{12} & p \varepsilon_{22}+q\left(\varepsilon_{33}+\varepsilon_{11}\right)-\lambda_{2} & 2 r \varepsilon_{23} \\
2 r \varepsilon_{13} & 2 r \varepsilon_{23} & p \varepsilon_{33}+q\left(\varepsilon_{11}+\varepsilon_{22}\right)-\lambda_{3}
\end{array} \quad \mid=0 \text { (12) }
$$

In equation (12), the strain tensor components $\varepsilon_{i j}$ (unitless) and the optical phonon deformation potential constants $p, q$, and $r$ (units of $\mathrm{cm}^{-2}$ ) are measured values for each crystal type. ${ }^{5}$ The difference between the Raman frequency of each phonon mode in the presence of stress, $\omega_{m}(m=1-3)$, and in the absence of stress, $\omega_{0}$, can be calculated from the eigenvalues $\lambda_{m}(m=1-3)$ of equation (12). The eigenvalues represent the frequency shifts ${ }^{5}$ where,

$$
\lambda_{m}=w_{m}^{2}+w_{0}^{2}\left[\mathrm{~cm}^{2}\right]
$$

The relation between the Raman frequency of each mode and the components of the strain tensor is given by:

$$
\Delta w_{m}=w_{m}-w_{0} \approx \frac{\lambda_{m}}{2 w_{0}}\left[\mathrm{~cm}^{-1}\right]
$$

In the absence of stress, these modes all have the same wavenumber $\omega_{0}=520 \mathrm{Rcm}^{-1}$; two are

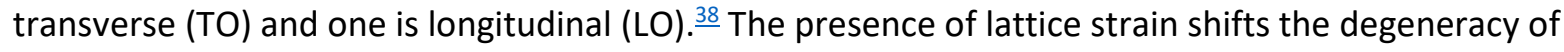
these modes and changes their wavenumbers. The new wavenumbers are related to the lattice strains $\varepsilon_{i j}$ by solving equation (12) for the eigenvalues. The optical phonon deformation potential coefficients $p, q$, and $r$ are measured by observing the changes in Raman wavenumber induced for known strains. The three eigenvalues of the secular equation, which indicate an orthotropic material, correspond to the shifts in Raman frequency of the three optical phonon modes. The strain components $\varepsilon_{i j}$ (unitless) are related to the stress components $\sigma_{i j}$ (in units of Pa) by Hooke's law,

$$
\{\varepsilon\}=[S]\{\sigma\}[\text { unitless }](15)
$$

where $[S]\left(\mathrm{Pa}^{-1}\right)$ is the elastic compliance matrix for a cubic crystal structure. $\frac{39}{}$ For a cubic material such as silicon, the elastic compliance matrix has the following form: $\underline{\underline{-3}}$

$$
[S]=\left[\begin{array}{cccccc}
* 20 c S_{11} & S_{12} & S_{13} & 0 & 0 & 0 \\
S_{12} & S_{22} & S_{23} & 0 & 0 & 0 \\
S_{13} & S_{23} & S_{33} & 0 & 0 & 0 \\
0 & 0 & 0 & S_{44} & 0 & 0 \\
0 & 0 & 0 & 0 & S_{55} & 0 \\
0 & 0 & 0 & 0 & 0 & S_{66}
\end{array}\right]\left[\mathrm{Pa}^{-1}\right](16)
$$

Theoretical calculations and experimental Raman investigations on single crystal silicon have shown that a uniaxial strain along one of the $<100>$ or $<111>$ directions results in the splitting of the triplet peak into a singlet and a doublet shifting with strain at two different rates. A shear stress completely removes the 
degeneracy and results in a splitting into three singlets. One of the singlets will not shift with stress while the other two will shift in opposite directions. Both of these cases result in an observed increase in the silicon band full width at half-maximum (FWHM) under non-polarized Raman measurements. Hydrostatic pressure was found to cause a linear shift in the triplet peak position without affecting its degeneracy..$^{40}$ Experimentally determined values of the phonon deformation potentials for single crystal silicon under hydrostatic pressure are $1.88 \pm 0.05 \mathrm{~cm}^{-1} / G P a$.

Since the structural layers in the PolyMUMPs process are doped polysilicon, the phonon deformation potentials were experimentally determined to assess the stress profiles obtained from micro-Raman spectroscopy. To determine the phonon deformation potentials, induced strain tests were performed by creating a known bending moment strain on a set of MUMPs polysilicon beams using a P-3500 strain indicator meter. The P-3500 is a precision instrument used with resistive strain gages for strain measurements. From controlled strain induction, precise wavenumber shifts are obtained using Raman spectroscopy which is then correlated to the induced strain value. Due to the average grain size of $30 \mathrm{~nm}$ in the polysilicon structures, the Raman profiles obtained are averaging over a large number of randomly oriented crystals. Hence, in spite of the fact that the applied global strain is uniaxial, the observed Raman shift from local crystallites can be expected to simulate that of hydrostatic pressure. The strain dependence values obtained for Poly1 and Poly2 were $2.19 \mathrm{~cm}^{-1} / G P a$ and $2.61 \mathrm{~cm}^{-1} / G P a$ respectively. ${ }^{4}$ These values for strain dependence were used to determine the relative strain in the MEMS structures for all stress profiles.

\section{On-Chip Test Structures}

To determine the analytical residual stress and Young's modulus for each polysilicon layer, on-chip test structures are used. The structures used include comb resonators and microbridge beams. Arrays of microbridge beam structures of lengths ranging from $100 \mu \mathrm{m}$ to $900 \mu \mathrm{m}$ in increments of $10 \mu \mathrm{m}$ are used to determine the residual stress for both Poly1 and Poly2 structural layers in the PolyMUMPs process. These structures buckle for stress values above the critical Euler stress. $\stackrel{41}{\text { Using an }}$ interferometric microscope (IFM), precise critical buckling beam lengths are readily determined. The buckling beam equation, solved for length $L$, is given by $\underline{35,42}$

$$
L=\sqrt{\frac{\pi^{2} t^{2} E}{3 \sigma}}[\mu m] \text { (17) }
$$

where $t(\mu \mathrm{m})$ is the beam thickness, $\sigma(\mathrm{Pa})$ is the residual stress, and $E(\mathrm{GPa})$ is the Young's modulus of the material. Length $L$ in equation (17) is the maximum length before buckling occurs. By knowing the elastic modulus of the material, the localized residual stress can be determined. Figure $\underline{\text { 8(a) }}$ illustrates an IFM image of buckled Poly1 and Poly2 microbridge beam arrays. 


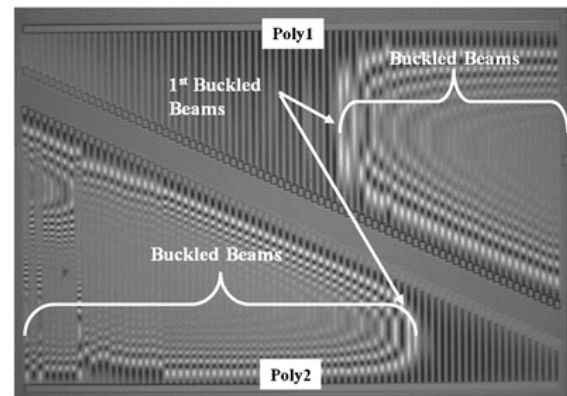

(a)

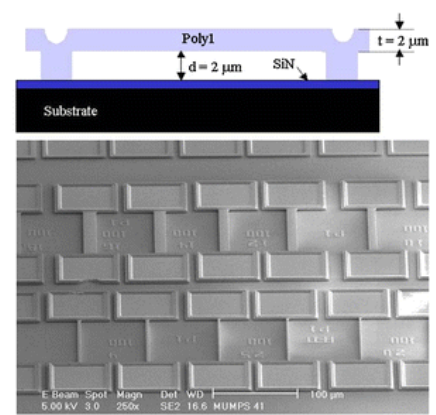

(b)

Fig. 8 (a) IFM image of buckled PolyMUMPs Poly 1 and Poly2 beams, (b) images of polysilicon microbridges used in micro-Raman spectroscopy measurements, top view is the 2D cross section of a typical beam

Young's modulus is the proportionality constant which relates stress and strain in a material by

$$
E=\frac{\text { stress }}{\text { strain }}=\frac{\sigma}{\varepsilon}\left[N / m^{2}\right]
$$

For very small strains, most materials obey Hooke's law; that is, they deform linearly with an applied load and return to their original shape when the load is removed. Since the load is proportional to stress and the deformation is proportional to strain, stress and strain are linearly related. The larger the value of Young's modulus of a material, the less it deforms for a given stress, thus the material is stiffer. The calculation of Young's modulus is directly related to the material density, which will be slightly different for films deposited under different conditions. Comb-drive resonators are commonly used to measure

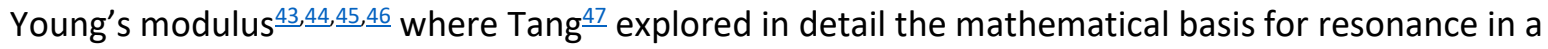
comb drive. Using the spring constant in the $\mathrm{x}$-direction, $k_{x}$, the resonant frequency can be calculated as:

$$
f=\frac{1}{2 \pi} \sqrt{\frac{k_{x}}{M}}=\frac{1}{2 \pi} \sqrt{\frac{24 E I_{z}}{\left(M_{p}+\frac{1}{4} M_{t}+\frac{12}{35} M_{b}\right) L^{3}}}[\mathrm{~Hz}]
$$

where $E(P a)$ is Young's modulus, $I_{z}\left(m^{4}\right)$ is the cross sectional moment of inertia for the beam with respect to the axis, $L(\mu \mathrm{m})$ is the beam length, and $M_{p}, M_{t}$, and $M_{b}$ are the mass of the plate, trusses, and beams $(\mathrm{kg})$ respectively. $\frac{47}{}$

The measured resonant frequency for Poly1 comb drive resonators is approximately $22.6 \pm 0.15 \mathrm{kHz}$ and $18.9 \pm 0.15 \mathrm{kHz}$ for Poly2 resonators. From equation (19), these resonant frequencies correspond to Young's modulus values of $131 \pm 2.0 \mathrm{GPa}$ for Poly1 and $162 \pm 2.0 \mathrm{GPa}$ for Poly2. The Young's modulus values are then applied to the critical buckling equation (equation (17)) to determine the localized residual stress level.

Series of Poly1 and Poly2 microbridge structures (Fig. $\underline{8(b)}$ ) were designed and fabricated in the PolyMUMPs process to be used with Raman Spectroscopy to assess the phosphorous implants. The polysilicon microbridge selected has dimensions of $100 \mu \mathrm{m}$-long with a width of $10 \mu \mathrm{m}$. Both ends of the microbridge test structure are anchored to a silicon nitride layer deposited on the silicon substrate. The microbridges are suspended $2 \mu \mathrm{m}$ above the substrate for Poly1 beams and $2.75 \mu \mathrm{m}$ for Poly2 beams. 


\section{Experimental Testing}

Micro-Raman spectroscopy is used to investigate and measure residual stress in unreleased and released polysilicon MEMS microbridge structures as shown in Fig. $7(\mathrm{~b})$. The Raman spectra were obtained using a Renishaw system 2000 Raman microscope in backscattering mode. The Raman excitation source is an Ar+ laser emitting at $514.5 \mathrm{~nm}$. The laser power is limited to $2.4 \mathrm{~mW}$ at the sample to minimize sample heating. Scanning was accomplished using a stepping XYZ stage with a $1 \mu \mathrm{m}$ resolution. Scans of the polysilicon microbridge structures were accomplished by focusing the laser through a microscope objective, resulting in a spatial resolution of approximately $1 \mu \mathrm{m}$. Polarization was not used for the Raman stress measurements. The frequency shifts in the Raman spectra were found by fitting the Raman peak with a Lorentzian function with an error of approximately $0.1 \mathrm{Rcm}^{-1}$. The Raman shift is then referenced to the Rayleigh scattering line to account for spectrometer variations.

Micro-Raman stress profiles were performed on all selected MEMS structures to determine a background residual stress level prior to the phosphorous implants. Following all implants, an oxidation/anneal was performed at a temperature of $900^{\circ} \mathrm{C}$ for 30 -min with an $\mathrm{O}_{2}$ gas flow rate of $1 \mathrm{l} / \mathrm{min}$. The oxidation/anneal step serves three purposes: 1 ) helps repair the crystal damage due to the implant; 2) it grows the nominal 50 Á oxide cap to minimize phosphorous outgassing; and 3) it allows diffusion of the implanted phosphorous ions within the polysilicon material to aid in achieving uniform doping concentrations. All samples were simultaneously annealed at $1,100^{\circ} \mathrm{C}$ for $5,10,15$, or 20 -min to eliminate time variations. At this anneal temperature, phosphorous readily diffuses which aids in dopant uniformity. Micro-Raman scans were performed following the implants and accompanying 30-min,

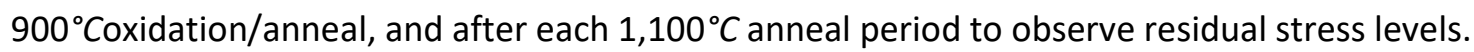

A four point probe setup was used to measure the resistivity from each implant dose. An HP4155A semiconductor parameter analyzer was used to measure the resistivity values of the implanted Poly 1 and Poly 2 microbridges. Beam resistance decreased from $415 \Omega$ to $86.5 \Omega$ for Poly1 beams and $820 \Omega$ to $79.7 \Omega$ for Poly 2 beams. From the resistivity measurements, the final polysilicon doping densities approximately match the doping levels predicted by the TSUPREM simulations. All ion implants were performed at low temperatures $\left(50^{\circ} \mathrm{C}\right)$ to prevent damage to the dice.

\section{Experimental Results}

Micro-Raman spectroscopy scans on $10 \mu m$-wide by $100 \mu m$-long unreleased Poly 1 and Poly2 microbridges were performed. Since identical microbridge test structures were used across different dice, micro-Raman stress profile comparisons can be made to determine implant and anneal affects on the polysilicon structural layers. All micro-Raman stress profiles presented are the average of three repeated scans and computed using the experimentally measured values for the phonon deformation potentials for Poly1 and Poly2 under hydrostatic pressure.

Figure 9(a) shows Poly1 stress profiles obtained from unreleased microbridges following the phosphorous implants and accompanying $15-\mathrm{min}, 1,100^{\circ} \mathrm{C}$ anneal. Each stress profile depicts a different implant dose. As shown in Fig. 9(a), the residual stress is reduced in the low dose implants $\left(5 \times 10^{15}\right.$ and $1 \times 10^{16}$ ions $\left./ \mathrm{cm}^{2}\right)$ to stress levels approaching $0 \mathrm{~Pa}$. In the higher implant doses $\left(3 \times 10^{16}, 5 \times 10^{16}\right.$, and $1 \times 10^{17}$ ions $\left./ \mathrm{cm}^{2}\right)$, the Raman stress profiles shift from a compressive (less than $0 \mathrm{~Pa}$ ) to a tensile stress (greater than $0 \mathrm{~Pa}$ ) and steadily increase as the implant dose is increased. The polysilicon grain size should be similar in all dice since all were annealed simultaneously; 
thus, the variation in measured stress profiles is due solely to minor variations in the MUMPs foundry process and the new doping concentrations. In addition, From Fig. 9(a), residual stress variations between the 100 (light line) and $200 \mathrm{keV}$ (bold line) implant energy levels appear to be very minimal. This result correlates very well with TSUPREM simulations for these implant power levels. As illustrated in Fig. 9(a), it appears the residual stress converts to a tensile stress following the $3 \times$ $10^{16}$ ions $/ \mathrm{cm}^{2}$ implant doses. This is a key observation such that on-chip buckling beam arrays should not buckle under tensile stress since buckling occurs only under compressive stress. Nearly identical Raman stress profiles were obtained for Poly2 microbridge beams with similar stress magnitudes as those shown in Fig. 9(a).

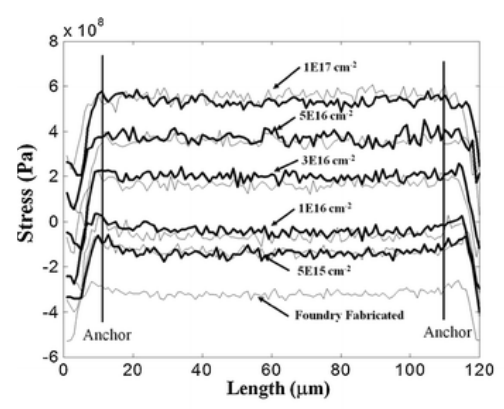

(a)

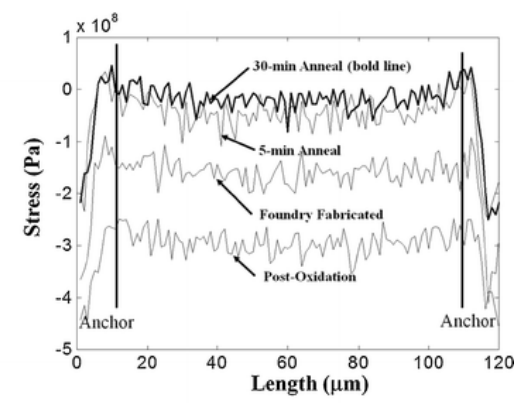

(b)

Fig. 9 (a) Poly 1 residual stress profiles measured using micro-Raman spectroscopy for $100 \mu \mathrm{m}$-long by $10 \mu \mathrm{m}$-wide unreleased beams following phosphorous implants at the doses listed for both the $100 \mathrm{keV}$ (lighter line) and $200 \mathrm{keV}$ (darker line) implant power levels followed by a 15 -min anneal at $1,100{ }^{\circ} \mathrm{C}$. (b) stress profiles illustrating stress changes in the Poly2 material layer during the key post-processing steps for the $200 \mathrm{keV}$, $1 \times 10^{16}$ ions $/ \mathrm{cm}^{2}$ phosphorous ion implant

Figure $\underline{9(b)}$ illustrates the stress profiles at each key post-processing step for the $200 \mathrm{keV}$, $1 \times 10^{16}$ ions $/ \mathrm{cm}^{2}$ phosphorus implant. Significant residual stress relaxation occurs in the polysilicon material layer following the post implant oxidation, and subsequent $1,100{ }^{\circ} \mathrm{C}$ anneal. As shown, the residual stress increases following the oxidation step which is a result of phosphorous outgassing. The outgassing creates an increased nonuniformity of the phosphorous dopant, thus creating higher stress gradients. Once the oxide cap ( $50 \AA)$ is grown, an $1,100{ }^{\circ} \mathrm{C}$ anneal is performed in which the residual stress magnitude rapidly decreases to levels much lower than the initial foundry fabricated level. The $1,100{ }^{\circ} \mathrm{C}$ anneal allows for rapid diffusion within the polysilicon structure, thus increasing dopant uniformity and minimizing potential stress gradients due to dopant irregularities. In addition, the grain size of polysilicon will increase, aiding in residual stress reduction, for an $1,100{ }^{\circ} \mathrm{C}$ annealing temperature as noted in several studies on the grain size effects on residual stress. $\underline{27}, \underline{43}, \underline{48}$ As shown in Fig. $\underline{9(b)}$, the 5min anneal time used for these experiments results in the most significant residual stress reduction. Minimal stress reduction occurs for longer anneal times; thus, stress reduction due to increased grain size appears to be minimal when compared to the increased dopant uniformity.

To validate the residual stress reduction due to the implants as shown by the Raman stress profiles in Fig. 9 , on-chip Poly1 and Poly 2 buckling beam arrays and comb drive resonators were fabricated to determine the material properties for each structural layer. Young's modulus was determined by measuring the resonance of the comb drive resonators before and after the phosphorous implants. The measured frequency for Poly1 resonators with a $5 \times 10^{15}$ ions $/ \mathrm{cm}^{2}$ implant dose averaged approximately $22.52 \pm 0.15 \mathrm{kHz}$ which corresponds to a Young's modulus of $129 \pm 2 \mathrm{GPa}$. A 
$1 \times 10^{16}$ ions $/ \mathrm{cm}^{2}$ implant dose provided an averaged measured frequency of $21.35 \pm 0.15 \mathrm{kHz}$ which corresponds to a Young's modulus of $116 \pm 2 \mathrm{GPa}$. The on-chip Young's modulus value decreased by approximately $13 \mathrm{GPa}$ between the $5 \times 10^{15}$ and the $1 \times 10^{16} \mathrm{ions} / \mathrm{cm}^{2}$ implant doses. Young's modulus is known to slightly decrease for increased doping concentrations in crystalline silicon. ${ }^{27, \underline{43}}$ Similar results were obtained for the Poly2 structural layer. The measured Young's modulus values are then used to calculate the analytical residual stress values in the polysilicon structural layers.

Following the MEMS release, IFM measurements were performed to determine the critical buckling lengths for the Poly1 (top) and Poly2 (bottom) buckling beam arrays following the implants and accompanying anneals. Figure 10(a) illustrates the critical buckling lengths of the MUMPs foundry fabrication arrays for both Poly1 and Poly2 structural layers. The buckling beam arrays shown in Fig. $10(\mathrm{~b})$ and (c) verify that residual stress reduction was achieved for the $5 \times 10^{15}$ and $1 \times 10^{16}$ ions $/ \mathrm{cm}^{2}$ dose ion implants and accompanying 15 -min, $1,100{ }^{\circ} \mathrm{C}$ anneals. From the critical buckling lengths and the measured Young's modulus for each structural layer, the residual stress levels can be determined. The micro-Raman stress profiles in Fig. 9(a) suggest that the residual stress for the $1 \times 10^{16}$ ions $/ \mathrm{cm}^{2}$ implant and 15 -min anneal case is near zero but still compressive. The IFM image of the buckling beam arrays shown in Fig. 10(c), supports this residual stress reduction. The resulting residual stress for the $1 \times 10^{16}$ ions $/ \mathrm{cm}^{2}$ implant was calculated to be $-2.11 \mathrm{MPa}$ for Poly 1 and $-1.52 \mathrm{MPa}$ for Poly2. From observed on-chip test structures, residual stress levels remain approximately the same for longer anneal times.

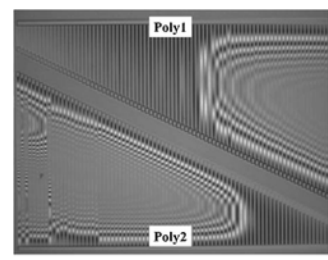

(a)

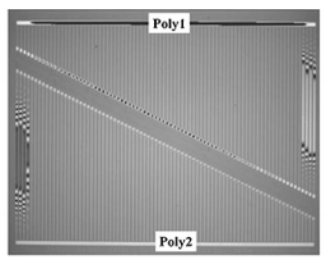

(b)

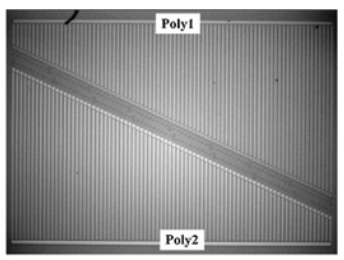

(c)

Fig. 10 IFM images of Poly1 (top) and Poly2 (bottom) buckled beam arrays for various 200 keV phosphorous implants with an accompanying $15-\min 1,100{ }^{\circ} \mathrm{C}$ anneal. (a) Foundry fabricated arrays, (b) $5 \times$ $10^{15}$ ions $/ \mathrm{cm}^{2}$ implant, and (c) $1 \times 10^{16}$ ions $/ \mathrm{cm}^{2}$ implant

For implant doses $\left(3 \times 10^{16}, 5 \times 10^{16}\right.$, and $1 \times 10^{17}$ ions $\left./ \mathrm{cm}^{2}\right)$ indicating a transition from compressive to tensile stress, following IFM analysis of on-chip buckling beam arrays show this transition was incorrect. The polysilicon structural layers appeared to have been inadvertently changed to another form due to the high implant doses. Since our interests were in evaluating stress reduction through Raman spectroscopy, no further analysis at these doping levels were accomplished. However, through on-chip IFM analysis of the buckling beam arrays associated with the $5 \times 10^{15}$ and $1 \times 10^{16}$ ions $/ \mathrm{cm}^{2}$ ion implant doses, the stress assessment correlates well with the residual stress profiles obtained using micro-Raman spectroscopy for unreleased MEMS microbridges for low implant doses. For low implant doses, the PolyMUMPs fabricated residual stress level in the structural layer was reduced by over $90 \%$ following post-processing.

\section{Conclusion}

In this paper, we demonstrated the successful use of micro-Raman Spectroscopy as a nonintrusive residual stress monitoring and measurement technique. Micro-Raman Spectroscopy was used to 
monitor residual stress levels in unreleased MEMS microbridge structures throughout post-processing implantation experiments. Through post-processing low dose phosphorous ion implants and accompanying $1,100{ }^{\circ} \mathrm{C}$ anneals, we verified residual stress reduction is possible using both microRaman spectroscopy and on-chip test structures. This research provides MEMS designers a straightforward avenue to assess inherent residual stresses and make modifications if needed through standard doping/anneal processes. The micro-Raman stress reduction was verified through on-chip buckling beam arrays with the $1 \times 10^{16}$ ions $/ \mathrm{cm}^{2}$ implant dose and accompanying anneal providing the minimum residual stress level. Young's modulus was measured using comb drive resonators. We verified resonance decreases with increased phosphorous concentrations as stated by MaierSchneider. $\underline{27}$ The Young's modulus decreased by approximately $13 \mathrm{GPa}$ in the Poly1 structural layer between the $5 \times 10^{15}$ and $1 \times 10^{16}$ ions $/ \mathrm{cm}^{2}$ ion implant doses. Lastly, we demonstrated the inherent MUMPs foundry fabricated residual stress levels can be significantly reduced by over $90 \%$ to stress levels less than -1.5 MPa following post-processing. The reduced stress levels can significantly improve device performance, reliability, and yield as MEMS devices become smaller in the future.

\section{Notes}

\section{Acknowledgements}

The financial support and sponsorship of this project were provided by the Air Force Research Laboratory (AFRL), Material and Manufacturing Directorate. The authors are also thankful to the AFRL Sensors Directorate for their technical assistance.

\section{References}

1. Koester, DA, Mahadevan, R, Hardy B, Markus KW (1999) MUMPs' ${ }^{\mathrm{TM}}$ Design Handbook Rev. 5, Cronos Integrated Microsystems, 3021 Cornwallis Road, Research Triangle Park, NC

2. Zou Q, Li Z, Liu L (1995) New methods for measuring mechanical properties of thin films in micromachining: beam pull-in (VPI) method and long beam deflection (LBD) method. Sens Actuators A 48:137-143

3. Anastassakis E, Pinczuk A, Burstein E, Pollak FH, Cardona M (1970) Effect of static uniaxial stress on the Raman spectrum of silicon. Solid State Commun 8:133-138

4. Starman LA, Lott JA, Amer MS, Cowan WD, Busbee JD (2003) Stress characterization of MEMS microbridges by micro-Raman spectroscopy. Sens Actuators A 104:107-116

5. De Wolf I (1996) Micro-Raman spectroscopy to study local mechanical stress in silicon integrated circuits. Semicond Sci Technol 11:139-154

6. Siakavellas M, Anastassikis E, Koltsas G, Nassiopoulos AG (1998) Micro-Raman characterization of stress distribution within free standing mono- and poly-crystalline silicon membranes. Microelectron Eng 41(42):469-472

7. Talaat H, Negm S, Schaffer HE, Kaltsas G, Nassiopoulos AG (2000) Micro-Raman analysis of polysilicon membranes deposited on porous silicon channels. J Non-Cryst Solids 266-269:13451349

8. Wu X, Yu J, Ren T, Liu L (2007) Micro-Raman spectroscopy measurement of stress in silicon. Microelectron J 38:87-90

9. Anaya J, Prieto AC, Martinez O, Torres A, Martin-Martin A, Jimenez J, Rodriquez A, Sangrador J, Rodriquez T (2011) Si and $\mathrm{Si}_{x} \mathrm{Ge}_{1-x}$ NWs studied by Raman spectroscopy. Phys Status Solidi C 8:1307-1310 
10. Li Q, Qiu W, Tan H, Guo J, Kang Y (2010) Micro-Raman spectroscopy stress measurement method for porous silicon film. Opt Lasers Eng 48:1119-1125

11. Gustafson PA, Haris SJ, O'Neill AE, Waas AM (2006) Measurement of biaxial stress states in silicon using micro-Raman spectroscopy. J Appl Mech Trans ASME 73:745-751

12. Kang Y, Qiu Y, Lei Z, Hu M (2005) An application of Raman spectroscopy on the measurement of residual stress in porous silicon. Opt Lasers Eng 43:847-855

13. Harris SJ, O'Neill AE, Yang W, Gustafson P, Boileau J, Weber WH, Majumdar B, Ghosh S (2004) Measurement of the state of stress in silicon with micro-Raman spectroscopy. J Appl Phys 96:7195-7201

14. Srikar VT, Swan AK, Ünlü MS, Goldberg BB, Spearing SM (2003) Micro-Raman measurement of bending stresses in micromachined silicon flexures. J Microelectromech Syst 12:779-787

15. Abel MR, Wright TL, King WP, Graham S (2007) Thermal metrology of silicon microstructures using Raman spectroscopy. IEEE Trans Compon Packag Tech 30:200-208

16. Jungchul L, Beechem T, Wright TL, Nelsonand BA, Graham S, King WP (2006) Electrical, thermal, and mechanical characterization of silicon microcantilever heaters. J Microelectromech Syst 15:1644-1655

17. Taniyama A, Hirai Y, Sugano K, Tabata O, Ikehara T, Tsuchiya T (2011) Local stress analysis of single crystalline silicon resonator using micro Raman spectroscopy. IEEE 24th Intl Conf on MEMS, pp 449-452

18. Xue C, Zheng L, Zhang W, Zhang B, Jian A (2006) A dynamic stress analyzer for microelectromechanical systems (MEMS) based on Raman spectroscopy. J Raman Spectrosc

19. Pan X, Tan CW, Miao J, Kasim J, Shen Z, Xie E (2009) The stress analysis of Si MEMS devices by micro-Raman technique. Thin Solid Films 517:4905-4908

20. De Wolf I, Kalicinski S, De Coster J, Oprims H (2009) Methods to measure mechanical properties of NEMS and MEMS: challenges and pitfalls. Material Research Society Symposium Proceedings, 1185

21. Miyatake T, Pezzotti G (2011) Tensor-resolved stress analysis in silicon MEMS device by polarized Raman spectroscopy. Phys Status Solidi A 208:1151-1158

22. Kaltsas G, Nassiopoulou AG, Siakavellas M, Anastassikis E (1998) Stress effect on suspended polycrystalline silicon membranes fabricated by micromachining of porous silicon. Sens Actuators A 68:429-434

23. Gundel P, Suwito D, Jager U, Heinz FD, Warta W, Schubert MC (2011) Comprehensive microscopic analysis of laser-induced high doping regions in silicon. IEEE Trans Electron Devices 58:2874-2877

24. Kwon WS, Alastair DT, Teo KH, Gao S, Ueda T, Ishigaki T, Kang KT, Yoo WS (2011) Stress evolution in surrounding silicon of $\mathrm{Cu}$-filled through-silicon via undergoing thermal annealing by multiwavelength micro-Raman spectroscopy. Appl Phys Lett 98:23

25. Porporati AA, Pezzotti G (2011) Polarized Raman spectroscopy clarifies the effect of crystal anisotropy on elastic stress fields developed on the surface of silicon single-crystal. Phys Status Solidi A 208:1093-1098

26. Howe RT, Boser BE, Pisano AP (1996) Polysilicon integrated microsystems: technologies and applications. Sens Actuators A 56:167-177

27. Maier-Schneider D, Köprülülü A, Ballhausen Holm S, Obermeier E (1996) Elastic properties and microstructure of LPCVD polysilicon films. J Micromech Microeng 6:436-446 
28. Bentez MA, Fonseca L, Esteve J, Benrakkad MS, Morante JR, Samitier J, Schweitz JA (1996) Stress-profile characterization and test-structure analysis of single and double ion-implanted LPCVD polycrystalline silicon. Sens Actuators A 54:718-723

29. Kawata M, Nadahara S, Shiozawa J, Watanabe M, Katoda T (1989) Characterization of stress in doped and undoped polycrystalline silicon before and after annealing or oxidation with laser raman spectroscopy. Research Center for Advanced Science and Technology, pp 407-411

30. TSUPREM-4 User's Manual (1993) Technology Modeling Associates, Inc., 3950 Fabian Way, Palo Alto, CA

31. Butler JT (1998) Development and packaging of microsystems using foundry services. Dissertation, Air Force Institute of Technology, Wright-Patterson AFB Ohio

32. Sinclair R (2001) Implant Sciences Corporation, 107 Audubon road, \#5, Wakefield MA

33. Pilkey WD (1994) Formulas for stress, strain, and structural matrices. Wiley \& Sons

34. Mastrangelo CH (1991) Thermal applications of microbridges. Dissertation, University of California Berkeley

35. Cowan WD (1998) Foundry microfabrication of deformable mirrors for adaptive optics, Dissertation, Air Force Institute of Technology, Wright-Patterson AFB Ohio

36. De Wolf I, Maes HE (1998) Mechanical stress measurements using micro-Raman spectroscopy. Microsyst Technol 5:13-17

37. Ganesan S, Maradudin A, Oitmaa J (1970) A lattice theory of morphic effects in crystals of the diamond structure. Ann Phys 56:556-594

38. Atkinson A, Jain SC (1999) Spatially resolved stress analysis using Raman spectroscopy. J Raman Spectrosc 30:885-891

39. Nye JF (1964) Physical properties of crystals. Oxford Science Pub, Oxford

40. Anastassakis E, Cantarere A, Cardona M (1990) Piezo-Raman measurements and anharmonic parameters in silicon and diamond. Phys Rev B 41:7529-7535

41. Elbrecht L, Storm U, Catanescu R, Binder J (1997) Comparison of stress measurement techniques in surface micromachining. J Micromech Microeng 7:151-154

42. Fang W, Wickert JA (1994) Post buckling of micromachined beams. J Micromech Microeng 4:116-122

43. Lee S, Cho C, Kim J, Park S, Yi S, Kim J, Cho D (1998) The effects of post-deposition processes on polysilicon Young's modulus. J Micromech Microeng 8:330-337

44. Maier-Schneider D, Maibach J, Obermeier E, Schneider DA (1995) Variations in Young's modulus and intrinsic stress of LPCVD-polysilicon due to high-temperature annealing. J Micromech Microeng 5:121-124

45. Boyd EJ, Uttamchandani D (2011) Measurement of the anisotropy of Young's modulus in singlecrystal silicon. J Microelectromech Syst 99:1-7

46. Kalicinski S, Tilmans HAC, Wevers M, De Wolf I (2009) A new characterization method for electrostatically actuated resonant MEMS: determination of the mechanical resonance frequency, quality factor and dielectric charging. Sens Actuators: A Phys 154:304-315

47. Chi-Keung Tang W (1990) Electrostatic comb drive for resonant sensor and actuator applications. Dissertation, University of California, Berkeley

48. Singh J, Chandra S, Chand A (1999) Strain studies in LPCVD polysilicon for surface micromachined devices. Sens \& Actuators 77:133-138 